Mediscope

\title{
Practice of contraceptive methods among the outdoor patients in a tertiary level hospital
}

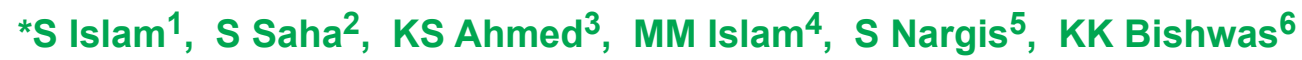

\begin{abstract}
The study to determine the practice contraceptive method among married women attended in the out-door patients in Ad-din Sakina Women's Medical College Hospital from 2nd November to 12th November in 2015. Nine hundred thirty five married women were interview on practice of contraceptive methods. Result shows highest number of choice among the respondents was oral pill, followed by condom, injection, IUCD. Through, contraceptive methods acceptance rate is increased still unmet need for contraceptive method was present. The country should come forward to face the challenges to safe country from disaster of over population.
\end{abstract}

Keywords: Practice, Contraceptive methods, Married women.

\section{Introduction}

Bangladesh is the most densely populated country in the world with an estimated population of 157.9 million and having population density 1070 per sq. $\mathrm{km}^{1}$ Singapore is only one country of the world have more population per sq. km than Bangladesh. We know that Singapore city is Singapore country. Bangladesh is one of the small countries of the world; it is already overburdened with its population. Bangladesh has very limited natural resources. Due to over population agriculture land and forest is rapidly decreasing. If the current population growth rate continued, it makes disaster to the country. Bangladesh is already facing lot of problems in related to over population. These are shortage of food, lack of accommodation, unemployment, pollutions, increasing unsocial activities, political unrest, lack of education, lack of health care etc.

1. Dr. Serajul Islam, Associate Professor, Department of Community Medicine, Ad-din Sakina Women's Medical College, Jashore. Email: dseraj02@gmail.com

2. Dr. Sanjoy Saha, Associate Professor, Department of Pharmacology \& Therapeutics, Ad-din Sakina Women's Medical College, Jashore.

3. Professor Dr. Khan Shakil Ahmed, Professor of Forensic Medicine \& Principal, Ad-din Sakina Women's Medical College, Jashore.

4. Dr. Mir Moyeedul Islam, Assistant Professor, Department of Pharmacology \& Therapeutics, Ad-din Sakina Women's Medical College, Jashore.

5. Dr. Susmita Nargis, Associate Professor, Department of Biochemistry, Ad-din Sakina Women's Medical College, Jashore.

6. Dr. Kishore Kumar Bishwas, Assistant Professor, Department of Paediatrics, Ad-din Sakina Women's Medical College, Jashore. 
Family Planning program has made substantial improvement in acceptance of contraceptive methods; the contraceptive prevalence rate is still $62 \%{ }^{2}$ Moreover, low literacy rate of female $69.90 \%, 1$ lack of women empowerment, male dominated culture especially in the rural areas, lack of safe motherhood, lack of availability of contraceptive methods, side-effects of contraceptive methods, misconception of religion, absence of family planning workers in the field, lack of supervision of field workers, lack good relationship health and family planning department, defective administrative between health and family planning department (unification of administration at ministry and upazilla level but different administration at district and division level) etc act as barriers to acceptance of contraceptive methods.

Now, Bangladesh is 3rd stage of demographic cycle. Here, death rate is declining and birth rate is also declining, but the population continues to grow slowly because births exceed deaths.

Though, Family Planning one of the successful programs in Bangladesh, but still unmet need for Birth Control is high. There are many causes of contraceptive method failure and drop-out. One of the cause is lack of proper counseling, all contractive method have of some side-effects. If the client's do not counseling about side-effects before the method given, when any side-effects occur, drop-out of method is happened. In case of condom, incorrect use of condom may cause of method failure. Lack of sexual pleasure another cause of drop-out of condom. Nonavailability of method may be one of main cause of unwanted pregnancy. Misconception about menstruation may cause unwanted pregnancy, some people belief without menses fertilization does not occur. In fact, fertilization may occur before menstruation. Through, Cu-T is semi permanent method, new type Cu-T (380-A model) can prevent contraception up to 10 years, but acceptance rate very low in Bangladesh. The main cause of low acceptance is side-effects, most of women child bearing age suffers from Pelvic Inflammatory Diseases (PID). Inadequate follow-up is important cause of dropout of contraceptive method. In absence of aseptic technique of insertion of $\mathrm{Cu}-\mathrm{T}$, cause infection which leads to drop-out, forget to take oral contraceptive, failure to bring contraceptive during visit to relative house. Some indirect causes also responsible for drop-out of contraceptive methods are-lack of partner support, lack of money to purchase contraceptives, negative attitude of community to family planning, judgmental attitude regarding sale of condom, lack of sex education etc.

The side-effects that headache to the clients are weight gain, amenorrhea, irregular and heavy bleeding, unwanted wetness and dryness of vagina, pain and loss of libido.

Bangladesh have high Maternal Mortality Rate (MMR) 1.78 per thousand live birth ${ }^{2}$ and Infant Mortality Rate (IMR) 28 per thousand live birth, ${ }^{2}$ through both MMR and IMR decreased in last decade but still high compare to many developing and developed countries. Birth control is directly related to women's health and child health, after one pregnancy the deficiency of nutrients is happened to women, it needs at least 4 to $5 y e a r s$ to recover these deficiency. But if the women become pregnant before mentioned time, the health of women is broken Sometimes, some women give birth to 5 to 6 children before 20 years of age and she look like old women. III health women give birth to Low Birth Weight (LBW) baby. Low Birth Weight baby have high mortality rate, due to lack of body resistant and unable to suck breast. High Infant Mortality Rate (IMR) is barrier to accept birth control, especially the permanent method.

\section{Materials and methods}


This is a cross-sectional type of descriptive study. The general objective was to determine practice of contraceptives among the married women. The population was married women attended in out- patients' department Ad-din Sakina medical college hospital, Jashore, west region of Bangladesh. The sample size is 935 married women in this hospital. Data were collected using questionnaire by asking questions about contraceptive practice.

\section{Results}

The total number of married women in the present study was 935 . Out of these 521 $(55.7 \%)$ use oral pill, Condom 204 (21.8\%) use Condom, 153 (16.4\%) use Injection, 42 (4.5\%), 13 (1.4\%), 2 (0.2\%) does not use any contraceptive method. Educational status among 935 respondents $452(48.3 \%)$ read up to SSC followed by $205(21.9 \%)$ read up to HSC followed by $125(13.4 \%)$ read up to class $V$ followed by $88(9.4 \%)$ read up to Bachelor followed by $57(6.1 \%)$ read up to Master followed by $8(0.9 \%)$ were illiterate. Educational status among the husband's of 935 respondents $324(34.7 \%)$ read up to SSC followed by $199(21.3 \%)$ read up to HSC followed by $168(18 \%)$ read up to Master followed 167 (17.9\%) read up to Bachelor followed $72(7.7 \%)$ read up to class $V$ followed $5(0.5 \%)$ were illiterate.

Table 01: Distribution of the respondents by their choice of contraceptive method:

\begin{tabular}{|c|c|c|}
\hline $\begin{array}{c}\text { Respondents } \\
\text { choice of } \\
\text { contractive } \\
\text { method }\end{array}$ & Frequency & Percentage \\
\hline Oral pill & 521 & 55.7 \\
\hline Condom & 204 & 21.8 \\
\hline Injectioon & 153 & 16.4 \\
\hline IUCD & 42 & 4.5 \\
\hline Others & 13 & 1.4 \\
\hline No method & 2 & 0.2 \\
\hline Table J2tabistriblution & $\mathbf{3 5}$ the respondents \\
\hline
\end{tabular}

by their educational status:

\begin{tabular}{|c|c|c|}
\hline $\begin{array}{c}\text { Respondents' } \\
\text { education }\end{array}$ & Frequency & Percent \\
\hline Illiterate & 8 & 0.9 \\
\hline Up to class V & 125 & 13.4 \\
\hline Up to SSC & 452 & 48.3 \\
\hline Up to HSC & 205 & 21.9 \\
\hline Up to Bachlor & 88 & 9.4 \\
\hline Up to Master & 57 & 6.1 \\
\hline Total & $\mathbf{9 3 5}$ & $\mathbf{1 0 0}$ \\
\hline
\end{tabular}

Table 03: Distribution of the respondents by their husbands' educational status:

\begin{tabular}{|c|c|c|}
\hline $\begin{array}{c}\text { Respondents' } \\
\text { husbands' } \\
\text { education }\end{array}$ & Frequency & $\begin{array}{c}\text { Percenta } \\
\text { ge }\end{array}$ \\
\hline Illiterate & 5 & 0.5 \\
\hline Up to class V & 72 & 7.7 \\
\hline Up to SSC & 324 & 34.7 \\
\hline Up to HSC & 199 & 21.3 \\
\hline Up to Bachelor & 167 & 17.9 \\
\hline Up to Master & 168 & 18 \\
\hline Total & $\mathbf{9 3 5}$ & $\mathbf{1 0 0}$ \\
\hline
\end{tabular}

\section{Discussion}

Oral pill is highest position in method choice , because it is low cost, easily available, highly effective, self-administration is possible, less side effects, do not interfere sexual intercourse, no need to convince husband, some beneficial effects make this method popular like reduce menstrual tension, cure dysmenorrhea, abnormal uterine bleeding. Condom is second position in client's method choice. Advantages of condom are easily available, low cost, no need to everyday use, no hormonal effects on body, almost side-effects nil, good method for childless couple, it is good method where wife do not live with husband, do not hamper breast feeding, it is not only prevent conception but also sexual diseases. Third choice contraceptive method 
is infection. The advantages injection are semi long term, it can prevent conception up to 3 months, do not interfere sexual intercourse, no need to use every day, in govt. program it is free of cost, no need to convince husband, good for lactating mother, main side effect is amenorrhea which cause headache to the user, they think bad blood accumulate in the abdomen, this side-effect sometime lead to drop-out. Forth choice of client is IUCD, it is long-term semi-permanent method, but clients do not use it, due lot of complications. Among the study women $99.8 \%$ women use contraceptive method which is very promising. The high acceptance of contraceptive methods is due to study population were urban peoples and educated population. Other cause was study done in tertiary level health care institution. But is not the national picture, if the study does in the rural acceptance rate will be much lower.

\section{Conclusion}

Bangladesh is very densely populated country of the world; it is already over burden for its population. Further increasing of population may bring disaster for the country. These over population may stop development activities of the country, these may create political unrest, unsocial may be increased, may be make the country poorer to poorer. This is right time to take step against population increasing. To declare "over population" is the number "1"problem of Bangladesh. Not only family planning but also all the Ministry should come forward to control growth rate. It needs social movement, political commitment, govt. should give leadership.

\section{References}

1. Bangladesh Bureau of Statistics (BBS)2015

2. Bangladesh Demographic and Health Survey 